\title{
Sensory and Physicochemical Properties and Stability of Folic Acid in a Pineapple Ready-to-Serve Beverage Fortified with Encapsulated Folic Acid
}

\author{
Geethi Pamunuwa $\mathbb{D}^{1},{ }^{1}$ Harshika Nilakshi $\mathbb{D}^{1},{ }^{1}$ Gagani Rajapaksha $\mathbb{D}^{1},{ }^{1}$ Farrah Shakoor $\mathbb{D}^{1}$, \\ and Desiree Nedra Karunaratne $\left.{ }^{2}\right)^{2}$ \\ ${ }^{1}$ Department of Horticulture and Landscape Gardening, Faculty of Agriculture and Plantation Management, \\ Wayamba University of Sri Lanka, Makandura, Gonawila (NWP) 60170, Sri Lanka \\ ${ }^{2}$ Department of Chemistry, Faculty of Science, University of Peradeniya, Peradeniya (CP) 20400, Sri Lanka
}

Correspondence should be addressed to Geethi Pamunuwa; geethip@wyb.ac.lk

Received 12 March 2021; Accepted 8 July 2021; Published 19 July 2021

Academic Editor: Barbara Speranza

Copyright $\odot 2021$ Geethi Pamunuwa et al. This is an open access article distributed under the Creative Commons Attribution License, which permits unrestricted use, distribution, and reproduction in any medium, provided the original work is properly cited.

\begin{abstract}
Fortification of food and beverages with folic acid is carried out frequently as a remedy to folic acid deficiency which causes serious health issues. This study was carried out to investigate the effect of incorporation of folic acid encapsulated alginate submicron particles in pineapple ready-to-serve (RTS) beverages. The encapsulation efficiency and loading capacity of the particles were $91.54 \pm 0.45 \%$ and $1.02 \pm 0.01 \%$, respectively. The photostability and thermal stability studies of folic acid revealed that encapsulation poses a protective effect on folic acid and that dark and refrigerated conditions contribute to higher stability of folic acid. In this study, sensory evaluation of the RTS beverages was carried out through both ranking tests and acceptance tests using a five-point hedonic scale. The sensory panel showed the highest preference to pineapple RTS with incorporated encapsulated folic acid at a quantity of its recommended daily intake $(400 \mu \mathrm{g} / 200 \mathrm{~mL})$ before heat treatment. Shelf-life evaluations were carried out through measuring physicochemical properties, and $\mathrm{pH}$, titratable acidity, and total soluble solids showed negligible or acceptable changes over two months. Folic acid degradation occurred due to heat treatment, but encapsulation in alginate submicron particles provided heat stability to folic acid. Thus, microencapsulated folic acid may be a successful carrier of folic acid which can be incorporated in beverages such as fortified pineapple RTS.
\end{abstract}

\section{Introduction}

Folic acid (vitamin B9) is an essential vitamin involved in fundamental functions of nucleic acid biosynthesis and protein metabolism of living organisms [1]. Consequently, deficiency of this essential vitamin leads to numerous deleterious health effects including neural tube defects. Increased consumption of folic acid has led not only to the elimination of deficiency symptoms but also to the reduction or elimination of complications associated with folic acid absorption or metabolism [1]. As an attempt to at least partially eliminate mainly folic acid deficiency, many countries have made fortification of many foods with folic acid mandatory. Folic acid fortification of enriched cereal grain products in the USA [2], folic acid fortification of white wheat flour in Canada [3], and folic acid fortification of bread in Australia [4] are prominent examples. Although mandatory folic acid fortification is not permitted, numerous countries allow voluntary folic acid fortification that has led to marketing of a number of folic acid-fortified foods including beverages and yogurt in those countries [4].

Numerous reports have demonstrated that, as expected, folic acid fortification of food is effective in eliminating deficiency symptoms of folic acid or in enhancing health of humans of many age groups and health conditions [5]. For instance, Williams et al. [6] reported that about $1326(95 \%$ 
confidence level) births that could have been affected with neural tube defects were obviated annually due to mandatory folic acid fortification in the USA over the time period from 1995 to 2011. Also, the folic acid deficiency among adults has reduced as a result of improved fortification of folic acid in Canada, which has led to decreased incidents of neural tube defects including spina bifida [7-9]. Furthermore, folic acid fortification has resulted in decreased folic acid deficiency of people according to a study carried out in Queensland, Australia [10]. The decrease in folic acid deficiency and avoidance of folic acid deficiency-related negative health effects through folic acid fortification highlight the importance of folic acid fortification of food.

Numerous exciting research studies, carried out with the aim of food fortification and/or nutraceutical development, have reported on encapsulated folic acid that exhibited ameliorated properties such as enhanced stability, $\mathrm{pH}$-dependent release, and improved bioaccessibility or bioavailability. For example, folic acid has been encapsulated in many food grade matrices such as alginate, alginate-pectin, whey protein, resistant starch, pectin-whey protein concentrate, maltodextrin-whey protein, horse chestnut starch, and $\beta$-cyclodextrin using one or more techniques including ionic gelation, nanospray drying, electrospraying, double emulsions, and spray drying [11-16]. A recent study conducted by Pamunuwa et al. portrayed the matrix-dependent and $\mathrm{pH}$-dependent release profiles of folic acid encapsulated nanoparticles made of alginate or alginate-pectin composites. Interestingly, nanoparticles made of $100 \%$ alginate showed enhanced release at both $\mathrm{pH} 6$ and $\mathrm{pH} 7.4$ which correspond to the optimum $\mathrm{pH}$ levels for the functioning of the folate receptors, proton-coupled proton transporters and reduced folate carriers, while showing no release at $\mathrm{pH} 2$, gastric $\mathrm{pH}[11]$. Also, a recent study carried out revealed the greater bioaccessibility of folic acid encapsulated alginate particles than folic acid encapsulated protein particles (personal communication). Considering the gastroprotective effect, according to no release at $\mathrm{pH} 2$ and enhanced release at higher $\mathrm{pH}$, favourable for better absorption of folic acid and higher bioaccessibility, the matrix composition of $100 \%$ alginate was further evaluated in this study for folic acid fortification of a fruit juice-based beverage.

Although numerous beverages fortified with folic acid are available in the market, reports on the utilization of encapsulated folic acid are rare. Encapsulation, however, is capable of providing thermostability to the encapsulated species as revealed in a number of occasions. Examples include thermoprotection of lactoferrin molecules due to encapsulation with alginate [17] and greater stability of $\beta$-carotene at $55^{\circ} \mathrm{C}$ due to encapsulation in alginate [18]. The commercial beverages fortified with free folic acid usually assure that the amount of actual folic acid content matches with the amount indicated in the label. For instance, the inlabel folic acid content of nine commercial folic acid-fortified beverages matched well with the experimental values obtained through solid-phase extraction followed by highpressure liquid chromatography according to a report by Perez Prieto et al. [19]. Interestingly, seven out of nine beverages, including fruit nectars, have reported the folic acid content before heat treatment in the label probably providing room for any degradation that may occur due to heat treatment. The effect on thermal treatment on the folic acid content, indeed, needs to be taken into account especially since folic acid-fortified beverages are consumed by vulnerable groups and higher or lower folic acid contents than the in-label content may cause health issues.

In this study, first, folic acid was encapsulated in alginate, and the particles were characterized for size, zeta potential, morphology, encapsulation efficiency, loading capacity, and successful encapsulation. Next, the photostability and thermal stability of the folic acid encapsulated particles were evaluated. After that, encapsulated folic acid-incorporated pineapple RTS beverages were made, and the accepted level of incorporation of folic acid was determined using a ranking test. The chosen sample from the ranking test was compared with regular pineapple RTS (control) with no fortification, using an acceptance test. The physicochemical parameters of regular RTS, RTS incorporated with empty alginate particles, RTS incorporated with free folic acid, and RTS incorporated with encapsulated folic acid were, then, evaluated to investigate the effect of folic acid incorporation on the physicochemical properties of the RTS beverages. Finally, the effect of thermal processing on the degradation of folic acid was studied using a simulated system.

\section{Materials and Methods}

2.1. Materials. Sodium alginate (>99.5\%) was purchased from HiMedia Laboratories Pvt. Ltd., India. Folic acid (97\%), calcium chloride (>99\%), sorbitan monooleate (Span 80 ), and alginate lyase were purchased from Sigma-Aldrich chemical company, USA. All other reagents were of analytical grade and used directly. Pineapple, sucrose, and citric acid were purchased from a local retail shop.

\subsection{Preparation of Folic Acid-Loaded Alginate Submicron} Particles. The submicron particles were prepared by using the ionic gelation method described by Pamunuwa et al. [11] with slight modifications. $\mathrm{pH}$ of an alginate solution $(0.3 \%$ $(\mathrm{w} / \mathrm{v})$ ) was adjusted to around 5. The alginate solution was stirred for 30 minutes after adding folic acid $(0.1 \%(\mathrm{w} / \mathrm{v}))$. Then, the solution was stirred with Span 80 for 2 hours at $1200 \mathrm{rpm}$ to obtain a homogeneous mixture. The above complex was gelated by dropwise addition of a calcium chloride solution while stirring at a speed of $1200 \mathrm{rpm}$ for 1 hour. The particle suspension was refrigerated overnight and centrifuged at $12,000 \mathrm{rpm}$ for 45 minutes to obtain a particle pellet which was then freeze-dried to obtain a free-flowing powder.

2.3. Particle Size and Zeta Potential. Size of the particles was measured using the dynamic light scattering technique after suspending the particles in distilled water and equilibrating at $25^{\circ} \mathrm{C}$ using a CILAS Nano DS Sn 110 particle size analyzer. Zeta potential of the particles was measured using Malvern Zetasizer Nano ZS (Malvern Instruments, UK) fitted with a red laser of $633 \mathrm{~nm}$, using the laser Doppler electrophoresis 
technique. The particles were suspended in deionized water and equilibrated at $25^{\circ} \mathrm{C}$ prior to analysis [20].

2.4. Scanning Electron Microscopy (SEM). SEM images of the freeze-dried submicron particles were obtained by placing the particles on metal stubs and depositing a thin gold coat on them under vacuum using a ZEISS EVO/LS15 scanning electron microscope [11].

2.5. Encapsulation Efficiency (EE) and Loading Capacity (LC). The encapsulation efficiency, in this context, is the amount of folic acid encapsulated in the particles compared to the total amount of folic acid used in the encapsulation process, expressed as a percentage. The encapsulation efficiency was determined by analyzing the absorbance of the supernatant obtained, after the centrifugation of the submicron particle suspension, at $\lambda_{\max }$ using a UV-visible spectrophotometer (Evolution 220, USA). The percentage encapsulation efficiency was calculated using the following formula [11]:

$$
\mathrm{EE}=\frac{\text { Amount }_{T}-\text { Amount }_{S}}{\text { Amount }_{T}} \times 100,
$$

where EE is the encapsulation efficiency (\%), Amount ${ }_{T}$ is the total amount or initial amount of folic acid, and Amount $_{S}$ is the amount of folic acid in supernatant.

The loading capacity (LC) was calculated using the following formula [11]:

$$
\mathrm{LC}=\frac{\text { loaded amount of folic acid }}{\text { mass of encapsulated particles }} \times 100 \text {. }
$$

2.6. Fourier-Transform Infrared Spectroscopy (FTIR). FTIR spectra of the folic acid-loaded submicron particles, empty particles, and free folic acid were obtained using a FTIR spectrophotometer (Jasco FT/IR 460 PLUS spectrometer, Japan) equipped with an attenuated total reflection (ATR) cell. About $10 \mathrm{mg}$ of the sample was introduced onto the ATR crystal before the acquisition of FTIR spectra over the scanning range of $400-4000 \mathrm{~cm}^{-1}$ at room temperature. The speed and resolution used in scanning were, respectively, $2 \mathrm{~mm} \mathrm{~s}^{-1}$ and $4 \mathrm{~cm}^{-1}[11]$.

2.7. Photostability and Thermal Stability of Folic Acid. Photostability of folic acid was investigated by keeping the samples, dry free folic acid and freeze-dried encapsulated folic acid, under dark conditions and exposing to sun light at room temperature separately. The samples were analyzed using UV-visible spectroscopy at $\lambda_{\max }$ after the enzymatic degradation of alginate using alginase as per the instructions of the supplier.

Thermal stability of folic acid was investigated by keeping the samples, dry free folic acid and freeze-dried encapsulated folic acid, at refrigerated conditions and at room temperature separately. The samples were analyzed after the degradation of alginate using alginase as per the instructions of the supplier.
2.8. Preparation of Pineapple Ready-to-Serve Beverages. RTS beverages were prepared using Sri Lanka standards (SLS 729: 2010) [21], and 5\% of fruit pulp was used. Pineapple pulp was strained using muslin cloth, and the juice was heated to $60^{\circ} \mathrm{C}$. Sugar and citric acid solution at $60^{\circ} \mathrm{C}$ were introduced to the juice after straining. $\mathrm{pH}$, titratable acidity (TA), and total soluble solids (TSS) were maintained, respectively, at approximately $3.5,<1 \%$, and $16 \%$. Folic acidadded beverages and the encapsulated folic acid-added beverages were also prepared (Table 1).

\subsection{Sensory Properties}

2.9.1. Ranking Test. A panel of 50 nontrained tasters carried out the ranking test on the day of production of RTS. The panellists were asked to rank the treatments using numbers 1 to 4 . Number 1 was for "most preferred," and number 4 was for "least preferred." The beverages used in the ranking test were $\mathrm{A}, \mathrm{B}, \mathrm{C}$, and $\mathrm{D}$ defined in Table 1.

2.9.2. Acceptance Test. A panel of 50 nontrained tasters carried out the acceptance tests. The sensory evaluation was carried out on the day of production for both a regular nonfortified pineapple RTS beverage (T1) and the best sample chosen from the ranking test (T2). The panellists were asked to indicate their observation using a five-point hedonic scale for colour, appearance, odour, texture, taste, sweetness, sourness, and overall acceptability.

2.10. Physicochemical Properties. Pineapple RTS was stored at room temperature $\left(30 \pm 2^{\circ} \mathrm{C}\right)$, and physicochemical parameters - $\mathrm{pH}, \mathrm{TA}$, and TSS-were measured initially, at one month, and at two months. $\mathrm{pH}$ was measured directly using an electronic $\mathrm{pH}$ meter with a probe. Titratable acidity was measured by titrating the juice with a $0.1 \mathrm{~N} \mathrm{NaOH}(\mathrm{aq})$ solution. The total soluble solids were measured using a handheld refractometer.

Equation (3) was used for the calculation of titratable acidity [22]:

$$
\% \operatorname{acid}\left(\frac{w t}{v o l}\right)=\frac{N \times V_{1} \times E q w t}{V_{2} \times 1000} \times 100,
$$

where $N$ is the normality of $\mathrm{NaOH}$ (aq), $V_{1}$ is the volume of the titrant $(\mathrm{mL}), V_{2}$ is the volume of the sample $(\mathrm{mL})$, and $\mathrm{Eq}$ wt is the equivalent weight of citric acid.

2.11. Folic Acid Retention during Heat Treatment. Folic acid retention during the sterilization of the RTS beverages was evaluated using simulated media. In brief, folic acid, either free or encapsulated, was introduced into a citric acid solution of $\mathrm{pH} 3.5$ which was then heat-treated at $100^{\circ} \mathrm{C}$ for $15 \mathrm{~min}$. Remaining folic acid in the solution was quantified using UV-visible spectroscopy.

2.12. Statistical Analysis. The values are stated as mean\pm standard deviation. Analysis of variance was used to analyze the data using Minitab (version 15 and 16) software, and sensory data were analyzed by the Friedman test. 
TABLE 1: Composition of prepared beverages.

\begin{tabular}{lc}
\hline $\begin{array}{c}\text { Treatment } \\
\text { (beverage) }\end{array}$ & Composition of the treatment of $200 \mathrm{~mL}$ \\
\hline Control & Regular pineapple RTS \\
A & Pineapple RTS + free folic acid $(400 \mu \mathrm{g})$ \\
B & $\begin{array}{c}\text { Pineapple RTS }+ \text { free folic acid }(200 \mu \mathrm{g}) \\
\text { C } \\
\text { Pineapple RTS }+ \text { encapsulated folic acid } \\
(400 \mu \mathrm{g})\end{array}$ \\
D & Pineapple RTS + encapsulated folic acid \\
& $(200 \mu \mathrm{g})$ \\
\hline
\end{tabular}

\section{Results and Discussion}

3.1. Particle Size and Zeta Potential. The diameter of the particles indicated by the peak of the frequency distribution (Dmode) was $426.5 \mathrm{~nm}$ revealing that the folic acid encapsulated particles were in the submicron range (ISO and STAM). Dmode, D50 (median), and Dmoy (average) of the particles were in close proximity, showing nearly a symmetrical size distribution. The coefficient of variation of the particles was $18.3 \%$, while the polydispersity index was $46.9 \%$, suggesting a relatively homogeneous size distribution. The zeta potential of the folic acid encapsulated particles was $-29.0 \mathrm{mV}$ with a zeta deviation of $5.3 \mathrm{mV}$ indicating that the particles are stable in aqueous media. This property is much useful in the event of incorporating these particles in an aqueous food medium [23].

3.2. Scanning Electron Microscopy. Scanning electron microscopy carried out to investigate the surface topology of the particles revealed the spherical shape of the particles used in this study (Figure 1). Furthermore, the particles assume a dry diameter of approximately $200 \mathrm{~nm}$ according to the micrographs.

3.3. Encapsulation Efficiency and Loading Capacity. The folic acid encapsulation efficiency of the alginate submicron particles was $91.54 \pm 0.45 \%$. Indeed, such high encapsulation efficiency for folic acid encapsulated submicron particles where alginate is the sole matrix is not reported in the literature. In fact, microparticles of which the matrix was alginate have shown a significantly lower encapsulation efficiency of $54.8 \pm 0.2 \%$ [12]. The high value obtained in this study justifies the use of the ionic gelation method and the conditions reported in this study for the preparation of folic acid-loaded alginate particles of submicron size. The folic acid loading capacity of the particles was $1.02 \pm 0.01 \%$. This result further indicates that the method and conditions used are very suitable.

3.4. Fourier-Transform Infrared Spectroscopy (FTIR). FTIR analysis was carried out to confirm the authenticity of the encapsulated material and the matrix and successfulness of the encapsulation of folic acid in the particles. The FTIR spectra of folic acid (FA), alginate empty particles (A), and folic acid encapsulated alginate particles (FA-A) are indicated in Figure 2.

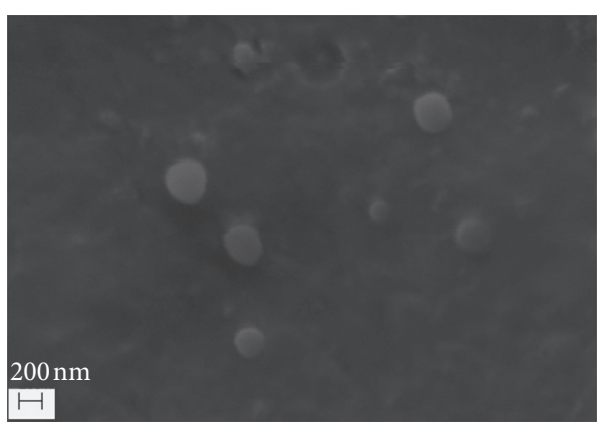

FIgURE 1: Scanning electron micrograph of folic acid encapsulated submicron particles.

FTIR spectrum of free folic acid confirmed the authenticity of the vitamin used in this study. The peaks in the range $3400-3600 \mathrm{~cm}^{-1}$ correspond to the stretching vibrations of the hydroxyl group of glutamic acid and $\mathrm{N}-\mathrm{H}$ group of the pterin ring. The peak corresponding to the $\mathrm{C}=\mathrm{O}$ stretching vibration appears at $1688.5 \mathrm{~cm}^{-1}$, while that corresponding to the bending vibration of $\mathrm{N}-\mathrm{H}$ appears at $1602.0 \mathrm{~cm}^{-1}$. The peaks at $1517.6 \mathrm{~cm}^{-1}$ and $1480.5 \mathrm{~cm}^{-1}$ are characteristic peaks indicating the presence of the phenyl and pterin rings of folic acid [24].

FTIR spectra of alginate empty particles (A) and folic acid encapsulated particles (FA-A) indicate the authenticity of alginate used in this study, and their comparison reveals successful encapsulation of folic acid in the particles. Stretching vibrations of hydroxyl groups are indicated by a strong broad band in the range $3000-3600 \mathrm{~cm}^{-1}$ of both spectra. However, the peak at $3327.5 \mathrm{~cm}^{-1}$ of A has shifted to a slightly lower frequency at $3322.4 \mathrm{~cm}^{-1}$ of FA-A due to the encapsulation of folic acid in FA-A. Also, the peak intensity of FA-A is higher than that of A, indicating successful encapsulation of folic acid and new hydrogen bond formation between alginate and folic acid in FA-A. Peaks corresponding to aliphatic $\mathrm{C}-\mathrm{H}$ stretching vibrations appear at $2925.0 \mathrm{~cm}^{-1}$ and $2854.0 \mathrm{~cm}^{-1}$ on both spectra. Notably, the peaks corresponding to asymmetric and stretching vibrations of carboxylate ions show a shift to higher frequencies on the spectrum of FA-A indicating the encapsulation of folic acid. In fact, these peaks are at $1595.0 \mathrm{~cm}^{-1}$ and $1415.6 \mathrm{~cm}^{-1}$ on the spectrum of $\mathrm{A}$, whereas these peaks are at $1602.0 \mathrm{~cm}^{-1}$ and $1416.7 \mathrm{~cm}^{-1}$ on the spectrum of FA-A. As expected, $\Delta v\left(\mathrm{COO}^{-}\right)$of both spectra was $179.4 \mathrm{~cm}^{-1}$ and $185.3 \mathrm{~cm}^{-1}$ indicating the interaction of calcium ions used in ionic gelation. C-O stretching vibrations of pyranosyl ring and uronic acid appear at higher frequencies on the spectrum of FA-A $\left(1086.2 \mathrm{~cm}^{-1}\right.$ and $943.1 \mathrm{~cm}^{-1}$, respectively) than on the spectrum of A $\left(1085.2 \mathrm{~cm}^{-1}\right.$ and $941.0 \mathrm{~cm}^{-1}$, respectively). Other noteworthy differences suggesting encapsulation of folic acid in FA-A are peaks of A at $888.5 \mathrm{~cm}^{-1}$ and $814.9 \mathrm{~cm}^{-1}$ corresponding to vibrations of mannuronic acid which are masked in the spectrum of FA-A [25].

In sum, the authenticity of folic acid and alginate used in this study, successful coordination of calcium ions to the carboxylate groups in the preparation of the submicron particles, and successful encapsulation of folic acid in the 


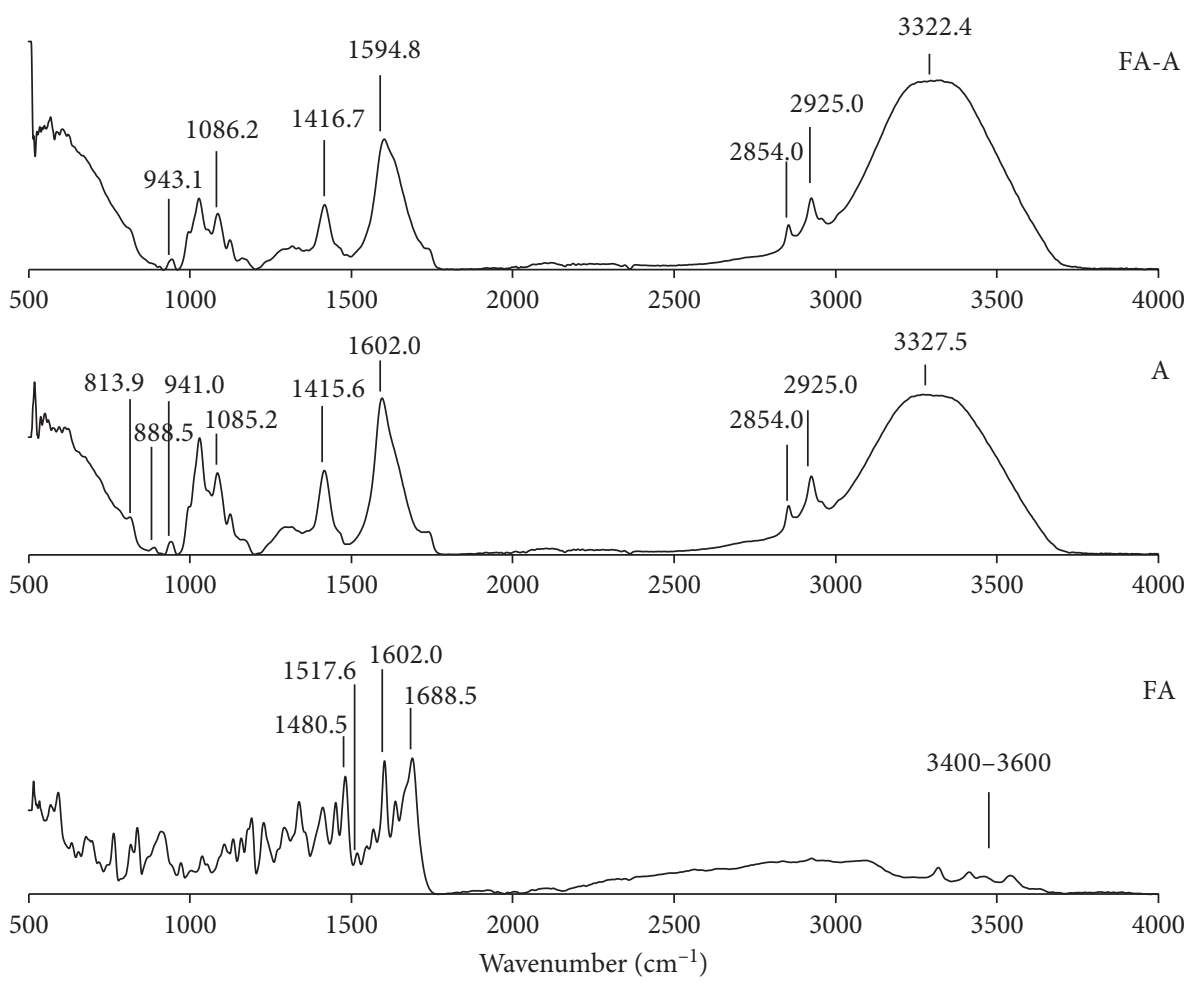

FIGURE 2: FTIR spectra of free folic acid (FA), alginate empty particles (A), and folic acid encapsulated particles (FA-A).

preparation of folic acid encapsulated submicron particles were confirmed through the FTIR analysis.

\subsection{Photostability and Thermal Stability of Folic Acid.} Photostability and thermal stability of free folic acid were compared to those of encapsulated folic acid in order to evaluate the effect of encapsulation on the stability of folic acid and to evaluate the optimum conditions for storage of folic acid prior to its utilization in the fortification of beverages.

Figure 3 illustrates the variation of percent degradation of folic acid, free or encapsulated, stored in the dark (covered) or stored exposed to daylight (exposed) with time. At the 95\% confidence level, the samples showed significantly different percent degradations in response to light with much higher degradation at exposed conditions than at covered conditions. Also, free FA showed significantly higher degradation than encapsulated FA. In fact, the degree of degradation in the decreasing order was free FA exposed $>$ FA-A exposed $>$ free FA covered $>$ FA-A covered. Thus, folic acid should always be stored in the dark. As expected, encapsulation in alginate confers a protective effect on folic acid whether this vitamin is stored in the dark or exposed to daylight. A considerable degree of degradation of folic acid occurred with time, showing the need to take protective measures. Statistical analysis reveals that encapsulated folic acid stored in the dark undergoes degradation to the minimum extent with time compared to different types of samples used in this study. Thus, the stated conditions are preferred for the storage of free folic acid, if necessary, before its use in the fortification of beverages.
Figure 4 illustrates the variation of percent degradation of folic acid, free or encapsulated, stored at $4^{\circ} \mathrm{C}$ or stored at room temperature (RT) with time. At the $95 \%$ confidence level, encapsulated folic acid showed significantly lower degradation than free folic acid. Also, storing at $4^{\circ} \mathrm{C}$ facilitated significantly lower degradation of folic acid than storing at room temperature. According to statistical analysis, the degree of folic acid degradation in the decreasing order was free $\mathrm{FA}, \mathrm{RT}>$ free $\mathrm{FA}, 4^{\circ} \mathrm{C}=\mathrm{FA}-\mathrm{A}$, $\mathrm{RT}>\mathrm{FA}-\mathrm{A}, 4^{\circ} \mathrm{C}$. Folic acid showed significant degradation with time, and the sample type and storage temperature showed a profound effect on the degradation. In sum, encapsulation of folic acid allows lesser degree of folic acid degradation, and storing the particles at $4^{\circ} \mathrm{C}$ enables further protection of folic acid.

Undoubtedly, encapsulation in alginate particles confers a protective effect on folic acid, and dark conditions together with refrigerated storage further enhance the stability of folic acid. Thus, freeze-dried folic acid encapsulated alginate particles may be provided as a sachet to the RTS beverage buyers to negate any deleterious effect on folic acid that may occur due to heat treatment of the beverages.

\subsection{Sensory Properties}

3.6.1. Ranking Test. Pineapple RTS with added folic acid, either regular or encapsulated, at two different levels $(200 \mu \mathrm{g}$ or $400 \mu \mathrm{g}$ ) was used in the ranking test. The four treatments are defined in Table 1 . There was a significant difference $(p<0.05)$ among the four treatments. The mean ranks obtained by the four treatments, A, B, C, and D, were 131.5, 


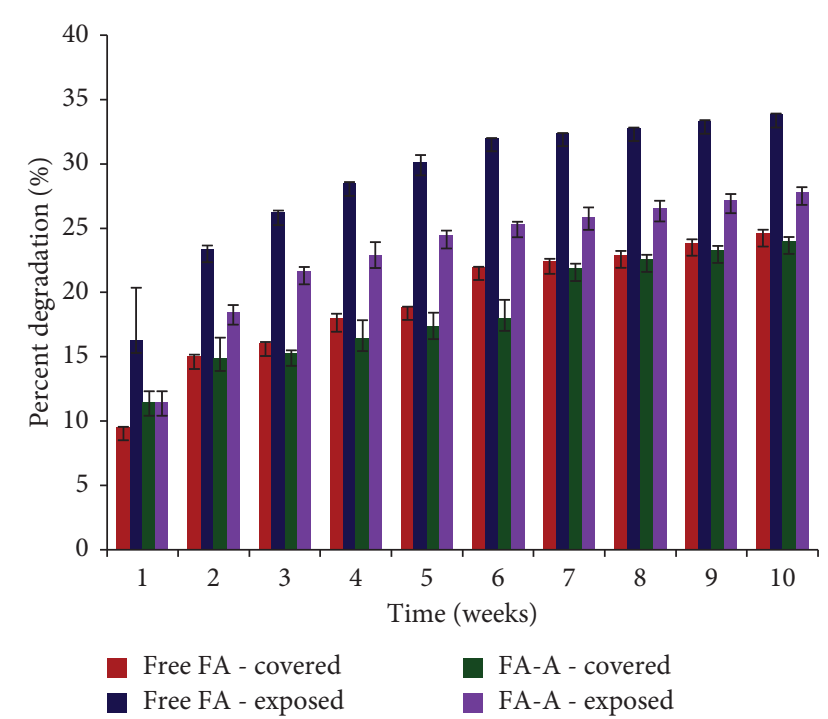

Figure 3: Percent degradation of folic acid as a result of photo effect with time (Free FA: free folic acid; FA-A: folic acid encapsulated submicron particles).

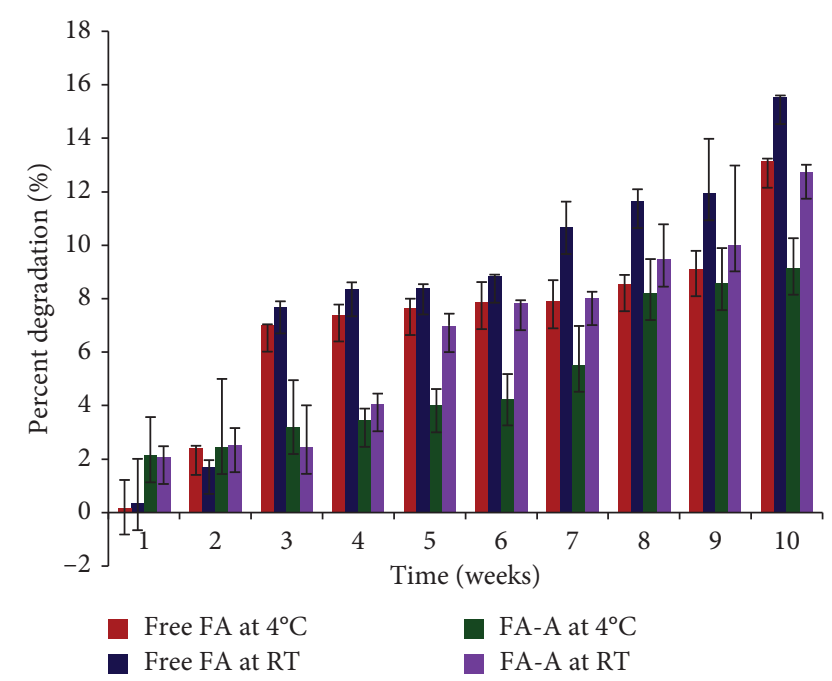

FIgUre 4: Percent degradation of folic acid as a result of temperature effect with time (Free FA: free folic acid; FA-A: folic acid encapsulated submicron particles).

113.3, 45.8, and 111.4, respectively. The ranks were obtained such that the treatment with the lowest mean rank was the most preferred, and vice versa. Also, treatment $\mathrm{C}$ was significantly different than all other treatments, while the other three treatments were similar according to critical absolute rank sum differences for all treatment comparisons at the 5\% significance level. This result demonstrates the suitability of encapsulation in masking any negative sensory effects of the encapsulated material-folic acid. The most preferred treatment C, which consisted of $400 \mu \mathrm{g}$ of folic acid in $200 \mathrm{ml}$ of beverage, was used in the acceptance test.

3.6.2. Acceptance Test. Regular pineapple RTS (T1) and pineapple RTS with $400 \mu \mathrm{g}$ of encapsulated folic acid in $200 \mathrm{ml}$ of beverage (T2) were used in the sensory evaluation.
The average scores of the two types of beverages for the sensory attributes considered are shown in Figure 5. Odour, sweetness, and sourness between the two treatments were similar $(p>0.05)$ which suggests that the incorporation of encapsulated folic acid has no effect on these properties. However, colour, appearance, texture, taste, and overall acceptability were better in encapsulated folic acid-added pineapple RTS beverages than in regular pineapple RTS beverage $(p<0.05)$. These results indicate that encapsulated folic acid has a positive effect on most attributes. Except sourness and odour, other attributes obtained a median rank of 4 or more in both treatments.

The expectation of the fortification of folic acid in the encapsulated form is to maximize its bioavailability and to minimize the organoleptic alteration to the beverage. According to the results of the sensory evaluation, it is clearly shown that the organoleptic properties of the beverage were either unaffected or enhanced by the incorporation of encapsulated folic acid.

Research on fortification of ready-to-serve beverages using nanostructured or submicron materials has been carried out with nutrients or bioactive compounds. Examples include fortification of beverages with vitamin D3 via lipid nanostructures [26] and incorporation of cinnamon oil into a chocolate drink [27]. Although folic acid fortification of beverages has been carried out and their consumption is reported from many countries [28], fortification of beverages with folic acid via nano- or submicron-sized particles is either scarce or nonexistent. Nevertheless, numerous exploratory studies on folic acid encapsulation targeting food fortification have been carried out, as mentioned previously, using matrices including alginate which was used in this study. This, however, is the first study investigating the incorporation of encapsulated folic acid in real fruit juicebased RTS beverages, and the revelation that encapsulated folic acid-fortified beverages show comparable sensorial properties as regular nonfortified beverages is very important as product development is concerned.

3.7. Physicochemical Properties. $\mathrm{pH}$, titratable acidity, and total soluble solids of the beverages are indicated in Table 2 . $\mathrm{pH}$ of the beverages increased with time from 3.5 to 3.6 or 3.7 over a period of two months. Yet, $\mathrm{pH}$ was below 4.0 which is acceptable for fruit juice-based RTS beverages according to Sri Lanka standards (SLS 729: 2010) [21]. The titratable acidity, however, was constant over two months according to statistical analysis. The total soluble solids were constant in all beverages except in the beverage where free folic acid was added for fortification (i.e., B2). Yet, the decrease was only $0.5^{\circ}$ Brix, and the value was acceptable. Interestingly, each property (i.e., $\mathrm{pH}, \mathrm{TA}$, and TSS) of all types of beverages (i.e., B1, B2, B3, and B4) was similar indicating that addition of empty alginate particles or free folic acid or encapsulated folic acid does not alter the physicochemical properties of pineapple RTS beverages. Thus, folic acid fortification of pineapple RTS can be carried out using either free folic acid or encapsulated folic acid posing no unfavourable effect on the beverages. 


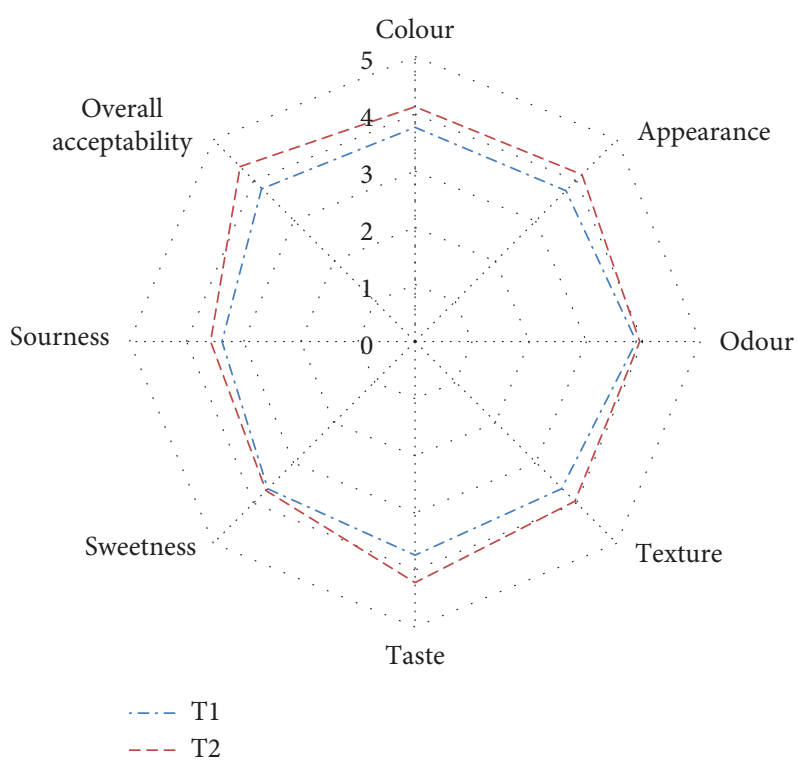

FIGURE 5: Average scores of regular nonfortified pineapple RTS beverage (T1) and pineapple RTS incorporated with encapsulated folic acid (T2) for sensory attributes.

TABle 2: Physicochemical properties of beverages over two months.

\begin{tabular}{|c|c|c|c|c|c|c|c|c|c|}
\hline \multirow[b]{2}{*}{$\begin{array}{l}\text { Type of } \\
\text { beverage }\end{array}$} & \multicolumn{3}{|c|}{$\mathrm{pH}$} & \multicolumn{3}{|c|}{ Titratable acidity (\%) } & \multicolumn{3}{|c|}{ Total soluble solids ( $\left.{ }^{\circ} \mathrm{Brix}\right)$} \\
\hline & Initial & $\begin{array}{l}\text { After one } \\
\text { month }\end{array}$ & $\begin{array}{c}\text { After two } \\
\text { months }\end{array}$ & Initial & $\begin{array}{c}\text { After one } \\
\text { month }\end{array}$ & $\begin{array}{l}\text { After two } \\
\text { months }\end{array}$ & Initial & $\begin{array}{l}\text { After one } \\
\text { month }\end{array}$ & $\begin{array}{c}\text { After two } \\
\text { months }\end{array}$ \\
\hline B1 & $3.5^{\mathrm{b}}$ & $3.6^{\mathrm{a}, \mathrm{b}}$ & $3.6^{\mathrm{a}}$ & $0.2^{\mathrm{a}}$ & $0.1^{\mathrm{a}}$ & $0.2^{\mathrm{a}}$ & $15.0^{\mathrm{a}}$ & $14.9^{\mathrm{a}}$ & $14.7^{\mathrm{a}}$ \\
\hline B2 & $3.5^{\mathrm{b}}$ & $3.5^{\mathrm{a}, \mathrm{b}}$ & $3.6^{\mathrm{a}}$ & $0.1^{\mathrm{a}}$ & $0.1^{\mathrm{a}}$ & $0.2^{\mathrm{a}}$ & $15.0^{\mathrm{a}}$ & $14.7^{\mathrm{a}, \mathrm{b}}$ & $14.5^{\mathrm{b}}$ \\
\hline B3 & $3.5^{\mathrm{b}}$ & $3.6^{\mathrm{a}}$ & $3.6^{\mathrm{a}}$ & $0.2^{\mathrm{a}}$ & $0.1^{\mathrm{a}}$ & $0.2^{\mathrm{a}}$ & $15.0^{\mathrm{a}}$ & $15.0^{\mathrm{a}}$ & $14.8^{\mathrm{a}}$ \\
\hline B4 & $3.5^{\mathrm{b}}$ & $3.6^{\mathrm{a}}$ & $3.7^{\mathrm{a}}$ & $0.1^{\mathrm{a}}$ & $0.1^{\mathrm{a}}$ & $0.2^{\mathrm{a}}$ & $15.0^{\mathrm{a}}$ & $14.9^{\mathrm{a}}$ & $14.8^{\mathrm{a}}$ \\
\hline
\end{tabular}

The numbers with the superscripts of the same letter in the same row of each property represent similar values at $p<0.05$ confidence level. The numbers of each column are similar at the 0.05 confidence level. B1: RTS beverage with encapsulated folic acid; B2: RTS beverage with free folic acid; B3: RTS beverage with empty alginate particles; B4: regular RTS beverage; RTS: ready to serve.

\subsection{Folic Acid Retention during Heat Treatment. The RTS} beverages were pasteurized after bottling, exposing to a temperature of $100^{\circ} \mathrm{C}$ for 20 minutes. A simulated system was utilized to determine the most appropriate method of folic acid fortification of the pineapple RTS beverages. In fact, both free folic acid-incorporated citrate solution of $\mathrm{pH}$ 3.5 and encapsulated folic acid-incorporated citrate solution of $\mathrm{pH} 3.5$ were treated with heat, and the remaining folic acid content was determined. The initial amount of folic acid introduced to $10 \mathrm{~mL}$ of solution was $2 \mathrm{mg}$. Folic acid remaining after heat treatment in the solution with free folic acid was $83 \pm 9 \mu \mathrm{g}$. Folic acid remaining in the solution with encapsulated folic acid was significantly higher and was $160 \pm 7 \mu \mathrm{g}$. In fact, the amount remaining in the solution with encapsulated folic acid was twofold the amount remaining in the solution with free folic acid. These results indicate that encapsulation in alginate particles poses a protective effect on folic acid during heat treatment. As expected, the amount of folic acid remaining in the solution with encapsulated folic acid was twofold $(106 \pm 17 \mu \mathrm{g})$ the amount remaining in the solution with free folic acid $(55 \pm 12 \mu \mathrm{g})$ after one month of storage at room temperature.
A similar steep initial decline of the remaining folic acid content in fortified fruit juices stored in the dark or exposed to light was reported by Frommherz et al. [29].

According to the degree of folic acid degradation shown by encapsulated folic acid in the simulated medium, the amount of folic acid remaining in the pineapple RTS beverages prepared in this study after heat treatment approximates to $16 \mu \mathrm{g} / 100 \mathrm{~mL}$. This value is similar to the folic acid content before UHT processing of an isotonic drink "Bisolan Citron" which is a commercially available drink. The nectars "Hero Wellbeing" and "Juver Enjoy" showed in-label folic acid contents of $660 \mu \mathrm{g} / 100 \mathrm{~mL}$ and $300 \mu \mathrm{g} / 100 \mathrm{~mL}$ before UHT processing [19], while pineapple RTS prepared in this study comprised a folic acid content of $200 \mu \mathrm{g} / 100 \mathrm{~mL}$ before heat treatment. These results suggest that the starting folic acid content may be increased to account for the possible losses due to heat treatment.

The results of this experiment of determining the folic acid retention during heat treatment are in line with the recent report by Črnivec et al. [30]. The release of folic acid into the medium (i.e., water) from alginate-pectin hybrid particles was approximately $90 \%$ at $75^{\circ} \mathrm{C}$, while that was 
negligible at $25^{\circ} \mathrm{C}$ by the end of $10 \mathrm{~min}$. The prominent reduction of folic acid from the encapsulated system, although less than free folic acid, may be due to the significant release of folic acid which may then prone to heat degradation. An interesting future study will be to evaluate the encapsulated folic acid retention as a function of different heat treatments. Microwave-assisted pasteurization may retain folic acid to a higher degree as holding time is much less in microwave-assisted pasteurization than in conventional heating. In fact, microwave-assisted pasteurization of fruit juice has shown increased retention of nutrients including vitamins such as vitamin $C$ [31] and many other bioactive compounds [32]. Ultrahigh-temperature (UHT) pasteurization may also show much less degradation of encapsulated folic acid as numerous other nonencapsulated nutrients including folate [33].

Considering the acidity of common fruit juice-based beverages, Črnivec et al. studied the release of folic acid from encapsulated particles at three $\mathrm{pH}$ levels: 2,3 , and 4 . A gradual increase in the folic acid release with time was observed at all $\mathrm{pH}$ levels. Also, the folic acid release was $\mathrm{pH}$ dependent. In fact, almost 100\% release was observed at $\mathrm{pH} 2$ and 4 , while only $25 \%$ release was observed at $\mathrm{pH} 3$ over a period of three months. Thus, folic acid release of approximately $25 \%$ or between $25 \%$ and $100 \%$ can be expected at $\mathrm{pH} 3.5$ used in this study. The study by Črnivec et al. further evaluated the percentage of folic acid remaining using three different percent recommended daily allowances (RDAs): 50\% RDA, 100\% RDA, and 200\% RDA of folic acid at the three $\mathrm{pH}$ levels stated above. Interestingly, the percentage of folic acid remaining was similar at all three RDA levels over the three-month period at both $\mathrm{pH} 3$ and $\mathrm{pH} 4$ [30]. These findings suggest that a folic acid initial RDA from $50 \%$ to $200 \%$ may be utilized in the beverages, including $100 \%$ RDA utilized in this study, with no variation in the percentage of folic acid remaining at $\mathrm{pH} 3.5$ which was maintained in the beverages of this study.

\section{Conclusions}

Alginate particles of submicron size encapsulating folic acid were successfully prepared for the folic acid fortification of a pineapple ready-to-serve beverage. Encapsulation of folic acid with alginate provided higher thermal stability and photostability to folic acid, indicating a possibility of formulating freeze-dried submicron particles in sachets to add into the beverages at the time of consumption. The sensory panel preferred encapsulated folic acid over free folic acid in beverages, and the concentration of encapsulated folic acid preferred most by the sensory panel was $400 \mu \mathrm{g} / 200 \mathrm{~mL}$. Interestingly, the sensory attributes of this fortified beverage with encapsulated folic acid $(400 \mu \mathrm{g} / 200 \mathrm{~mL})$ were either accepted equally or accepted at a higher degree compared to regular nonfortified pineapple ready-to-serve beverages by the sensory panel. The estimated folic acid retention during heat treatment, studied using a simulated system, was $16 \mu \mathrm{g} /$ $100 \mathrm{~mL}$ which was comparable to a commercial isotonic drink. However, the initial concentration of encapsulated folic acid $(400 \mu \mathrm{g} / 200 \mathrm{~mL})$ can be further increased to be in par with many other commercial beverages, and heat treatments with smaller holding times or nonthermal methods may be utilized for pasteurization to increase folic acid retention. In sum, folic acid encapsulated alginate submicron particles may be used for the folic acid fortification of fruit juice-based ready-to-serve beverages successfully with a final folic acid level in par with commercial fortified beverages.

\section{Data Availability}

The results' data used to support the findings of this study are included within the article.

\section{Conflicts of Interest}

The authors declare no conflicts of interest.

\section{Acknowledgments}

This work was supported by the Wayamba University of Sri Lanka, Sri Lanka (Grant no. SRHDC/RP/04/16-14 (R2)) and Ministry of Science, Technology and Research, Sri Lanka (Grant no. MTR/TRD/AGR/3/2/05).

\section{References}

[1] R. K. Saini, S. H. Nile, and Y.-S. Keum, "Folates: chemistry, analysis, occurrence, biofortification and bioavailability," Food Research International, vol. 89, pp. 1-13, 2016.

[2] S. D. Grosse, R. J. Berry, J. Mick Tilford, J. E. Kucik, and N. J. Waitzman, "Retrospective assessment of cost savings from prevention," American Journal of Preventive Medicine, vol. 50, no. 5, pp. S74-S80, 2016.

[3] Y.-M. Chan, A. J. MacFarlane, and D. L. O’Connor, "Modeling demonstrates that folic acid fortification of whole-wheat flour could reduce the prevalence of folate inadequacy in Canadian whole-wheat consumers," The Journal of Nutrition, vol. 145, no. 11, pp. 2622-2629, 2015.

[4] M. A. Lawrence, W. Chai, R. Kara, I. H. Rosenberg, J. Scott, and A. Tedstone, "Examination of selected national policies towards mandatory folic acid fortification," Nutrition Reviews, vol. 67, no. suppl_1, pp. S73-S78, 2009.

[5] C. M. Pfeiffer, M. R. Sternberg, M. Zhang et al., "Folate status in the US population $20 \mathrm{y}$ after the introduction of folic acid fortification," The American Journal of Clinical Nutrition, vol. 110, no. 5, pp. 1088-1097, 2019.

[6] J. Williams, C. T. Mai, J. Mulinare et al., "Updated estimates of neural tube defects prevented by mandatory folic acid fortification-United States, 1995-2011," Morbidity and Mortality Weekly Report, vol. 64, no. 1, p. 1, 2015.

[7] J. G. Ray, "Folic acid food fortification in Canada," Nutrition Reviews, vol. 62, no. suppl_1, pp. S35-S39, 2004.

[8] P. De Wals, F. Tairou, M. I. Van Allen et al., "Reduction in neural-tube defects after folic acid fortification in Canada," New England Journal of Medicine, vol. 357, no. 2, pp. 135-142, 2007.

[9] P. De Wals, F. Tairou, M. I. Van Allen et al., "Spina bifida before and after folic acid fortification in Canada," Birth Defects Research Part A: Clinical and Molecular Teratology, vol. 82, no. 9, pp. 622-626, 2008.

[10] A. Slagman, L. Harriss, S. Campbell, R. Muller, and R. McDermott, "Low proportions of folic acid deficiency after 
introduction of mandatory folic acid fortification in remote areas of northern Queensland, Australia: a secondary health data analysis," Biomarkers, vol. 24, no. 7, pp. 684-691, 2019.

[11] G. Pamunuwa, N. Anjalee, D. Kukulewa, C. Edirisinghe, F. Shakoor, and D. N. Karunaratne, "Tailoring of release properties of folic acid encapsulated nanoparticles via changing alginate and pectin composition in the matrix," Carbohydrate Polymer Technologies and Applications, vol. 1, Article ID 100008, 2020.

[12] H. Madziva, K. Kailasapathy, and M. Phillips, "Alginatepectin microcapsules as a potential for folic acid delivery in foods," Journal of Microencapsulation, vol. 22, no. 4, pp. 343-351, 2005.

[13] R. Pérez-Masiá, R. López-Nicolás, M. J. Periago, G. Ros, J. M. Lagaron, and A. López-Rubio, "Encapsulation of folic acid in food hydrocolloids through nanospray drying and electrospraying for nutraceutical applications," Food Chemistry, vol. 168, pp. 124-133, 2015.

[14] E. Assadpour, Y. Maghsoudlou, S.-M. Jafari, M. Ghorbani, and M. Aalami, "Evaluation of folic acid nano-encapsulation by double emulsions," Food and Bioprocess Technology, vol. 9, no. 12, pp. 2024-2032, 2016 a.

[15] E. Assadpour, Y. Maghsoudlou, S.-M. Jafari, M. Ghorbani, and M. Aalami, "Optimization of folic acid nano-emulsification and encapsulation by maltodextrin-whey protein double emulsions," International Journal of Biological Macromolecules, vol. 86, pp. 197-207, $2016 \mathrm{~b}$.

[16] M. Ahmad, S. Qureshi, S. Maqsood, A. Gani, and F. A. Masoodi, "Micro-encapsulation of folic acid using horse chestnut starch and $\beta$-cyclodextrin: microcapsule characterization, release behavior \& antioxidant potential during GI tract conditions," Food Hydrocolloids, vol. 66, pp. 154-160, 2017.

[17] Q. Li, H. Lan, and Z. Zhao, "Protection effect of sodium alginate against heat-induced structural changes of lactoferrin molecules at neutral pH," LWT, vol. 99, pp. 513-518, 2019.

[18] Z. Zhang, R. Zhang, and D. J. McClements, "Encapsulation of $\beta$-carotene in alginate-based hydrogel beads: impact on physicochemical stability and bioaccessibility," Food Hydrocolloids, vol. 61, pp. 1-10, 2016.

[19] S. Pérez Prieto, B. Cancho Grande, S. García Falcón, and J. Simal Gándara, "Screening for folic acid content in vitaminfortified beverages," Food Control, vol. 17, no. 11, pp. 900-904, 2006.

[20] G. Pamunuwa, V. Karunaratne, and D. Karunaratne, "Effect of lipid composition on in vitro release and skin deposition of curcumin encapsulated liposomes," Journal of Nanomaterials, vol. 2016, Article ID 4535790, 9 pages, 2016.

[21] "Sri Lanka Standard 729:UDC 663.81, Specification for ReadyTo-Serve Fruit Drinks (First Revision)," Sri Lanka Standards Institution, Colombo, Sri Lanka, 2010.

[22] G. D. Sadler and P. A. Murphy, "pH and titratable acidity," Food Science Texts Series, Springer, Boston, MA, USA, pp. 219-238, 2010.

[23] C. I. C. Crucho and M. T. Barros, "Polymeric nanoparticles: a study on the preparation variables and characterization methods," Materials Science and Engineering: C, vol. 80, pp. 771-784, 2017.

[24] Y. Y. He, X. C. Wang, P. K. Jin, B. Zhao, and X. Fan, "Complexation of anthracene with folic acid studied by FTIR and UV spectroscopies," Spectrochimica Acta Part A: Molecular and Biomolecular Spectroscopy, vol. 72, no. 4, pp. 876-879, 2009.
[25] S. K. Papageorgiou, E. P. Kouvelos, E. P. Favvas, A. A. Sapalidis, G. E. Romanos, and F. K. Katsaros, "Metalcarboxylate interactions in metal-alginate complexes studied with FTIR spectroscopy," Carbohydrate Research, vol. 345, no. 4, pp. 469-473, 2010.

[26] M. Mohammadi, A. Pezeshki, M. Mesgari Abbasi, B. Ghanbarzadeh, and H. Hamishehkar, "Vitamin D3-loaded nanostructured lipid carriers as a potential approach for fortifying food beverages; in vitro and in vivo evaluation," Advanced Pharmaceutical Bulletin, vol. 7, no. 1, pp. 61-71, 2017.

[27] D. R. A. Muhammad, C. G. Gonzalez, A. Sedaghat Doost, D. Van de Walle, P. Van der Meeren, and K. Dewettinck, "Improvement of antioxidant activity and physical stability of chocolate beverage using colloidal cinnamon nanoparticles," Food and Bioprocess Technology, vol. 12, no. 6, pp. 976-989, 2019.

[28] A. Ahmad and Z. Ahmed, "Fortification in beverages," Production and Management of Beverages, Woodhead Publishing, Sawston, UK, pp. 85-122, 2019.

[29] L. Frommherz, Y. Martiniak, T. Heuer, A. Roth, S. E. Kulling, and I. Hoffmann, "Degradation of folic acid in fortified vitamin juices during long term storage," Food Chemistry, vol. 159, pp. 122-127, 2014.

[30] I. G. Črnivec, K. Istenič, M. Skrt, and N. P. Ulrih, "Thermal protection and $\mathrm{pH}$-gated release of folic acid in microparticles and nanoparticles for food fortification," Food \& Function, vol. 11, no. 2, pp. 1467-1477, 2020.

[31] S. M. B. Hashemi, A. Gholamhosseinpour, and M. Niakousari, "Application of microwave and ohmic heating for pasteurization of cantaloupe juice: microbial inactivation and chemical properties," Journal of the Science of Food and Agriculture, vol. 99, no. 9, pp. 4276-4286, 2019.

[32] B. Pérez-Grijalva, M. Herrera-Sotero, R. Mora-Escobedo et al., "Effect of microwaves and ultrasound on bioactive compounds and microbiological quality of blackberry juice," LWT, vol. 87, pp. 47-53, 2018.

[33] H. Zhang, G. Önning, A. Ö. Triantafyllou, and R. Öste, "Nutritional properties of oat-based beverages as affected by processing and storage," Journal of the Science of Food and Agriculture, vol. 87, no. 12, pp. 2294-2301, 2007. 